\title{
Prevalence and associated factors for needlestick and sharp injuries (NSIs) among dental assistants in Jeddah, Saudi Arabia
}

\author{
Lama AIDakhil ${ }^{1,2}$, Nagarajkumar Yenugadhati ${ }^{1,2}$, Ohoud Al-Seraihi ${ }^{3}$ and Mustafa Al-Zoughool ${ }^{1,2^{*}}$ (D)
}

\begin{abstract}
Background: Dental personnel are subject to exposure to a number of occupational factors including needlestick and sharp injuries (NSIs). Our study aims to address knowledge gaps on prevalence and associated factors for needlestick and sharp injuries (NSIs) for the first time in Saudi Arabia.

Methods: This cross-sectional study was conducted on a sample of 450 dental assistants recruited from 40 randomly selected private clinics in Jeddah, Saudi Arabia. Data on demographic characteristics, history of NSIs, nature of work, compliance with infection control protocols, and knowledge of infection control procedures and disease transmission were collected using a self-administered questionnaire. Logistic regression analysis was used to assess factors associated with NSIs; unadjusted and adjusted odds ratios (aORs) and their respective 95\% confidence intervals (Cls) were computed.

Results: About three in ten dental assistants experienced at least one NSI $(29.8 \%, 95 \% \mathrm{Cl} 25.6-34.2 \%)$ in private dental clinics. Lack of adequate knowledge of infection control procedures and disease transmission, noncompliance with infection control protocol of vaccination against hepatitis B virus, and attending 12 or less number of patients daily were significantly associated with increased risk of NSIs ( $p \leq 0.05$ ); adjusted odds ratios ( $95 \% \mathrm{Cl}$ ) were 1.87 (1.18-2.97), 1.89 (1.05-3.41), and 1.63 (1.03-2.56), respectively. In addition, dental assistants working in $45.8 \%$ of dental clinics that had no infection control unit were positively associated with higher NSI risk $(\mathrm{aOR}=2.28,95 \% \mathrm{Cl} 1.45-3.57)$.

Conclusion: Our study reported the prevalent nature of NSIs among dental assistants in Saudi Arabia and identified key factors that could be targeted to mitigate this preventable condition. Dental assistants would benefit from proper training on infection control protocols and procedures.
\end{abstract}

Keywords: Healthcare workers, Dental assistants, Needlestick and sharp injuries, Infection control, Saudi Arabia

\section{Background}

Healthcare workers (HCWs) represent $12 \%$ of the global workforce $[1,2]$. The risk of occupational exposure to infectious diseases is high among HCWs due to the nature of their work and proximity to infected patients rendering them susceptible to direct (e.g., through airborne

\footnotetext{
* Correspondence: zoughoolm@ksau-hs.edu.sa

${ }^{1}$ King Abdullah International Medical Research Center (KAIMRC), Riyadh, Kingdom of Saudi Arabia

${ }^{2}$ Department of Community and Environmental Health, College of Public Health and Health Informatics, King Saud bin Abdulaziz University for Health Sciences, Mail Code 2350, P.O. Box 22490, Riyadh 11426, Kingdom of Saudi Arabia

Full list of author information is available at the end of the article
}

transmission) or indirect (contamination of instruments or surfaces) transmission of infection.

Contaminated needlestick and sharp injuries (NSIs) are the most common sources of infection among HCWs [2]. Approximately 3 out of 35 million HCWs worldwide experience needlestick injuries (NSIs) annually, exposing them to blood-borne pathogens $[2,3]$. Although as many as 20 different pathogens could be transmitted by NSIs [4], hepatitis B virus (HBV), hepatitis $\mathrm{C}$ virus (HCV), and human immunodeficiency virus (HIV) constitute the majority of blood-borne infections transmitted post-injury. Percutaneous occupational exposure accounts to approximately $37 \%$ of $\mathrm{HBV}, 39 \%$ of

(C) The Author(s). 2019 Open Access This article is distributed under the terms of the Creative Commons Attribution 4.0 International License (http://creativecommons.org/licenses/by/4.0/), which permits unrestricted use, distribution, and 
$\mathrm{HCV}$, and $4.4 \%$ of HIV cases among HCWs [5]. As dental practice involves regular use of sharp instruments, and exposure to saliva, blood, and naturally occurring oral bacterial flora [6], dentists were more prone to hepatitis B infection than the general adult population [7]. In addition to the possibility of transmission of infection, consequences of NSI affect the daily life of HCWs causing stress and anxiety and in extreme cases disability and mortality [8-10].

Although previous studies reported some factors associated with increased risk of NSIs among HCWs, the reported factors varied by profession and geographic region. For example, experience of the practitioner, number of patients attended on a daily basis, recapping needles, knowledge of infectious diseases, and compliance with infection control protocols were among personal factors linked to NSIs among dentists in Taiwan [11]. However, in another study among Mangolian healthcare workers [12], longer work hours and number of injections administered in a day were associated with higher risk. Procedures such as needle recapping were predominant among healthcare workers experiencing NSI in Kabul [13]. Perceptions of medical students towards NSI risk influenced their risk of injury in Serbia [14]. The World Health Organization (WHO) emphasizes the implementation of universal infection prevention measures and the need for properly training HCWs in reducing the prevalence of NSIs in a healthcare setting [15].

The dearth of literature on NSI risk among dental assistants in Saudi Arabia and rest of the world, especially in often overlooked private sector, prompted us to address this important research gap. For the first time in Saudi Arabia, the present study determined the burden of NSIs among dental assistants and identified associated factors for NSIs from demographic characteristics, nature of work, compliance with various infection control protocols, and knowledge of infection control procedures and disease transmission.

\section{Methods}

This cross-sectional study was conducted on a sample of dental assistants working in private dental clinics in Jeddah, Saudi Arabia, between June and September 2017 to determine the prevalence of NSIs and their associated factors. Dental assistants comprised of all qualified healthcare workers, such as nurses that assisted dentists with patient management in dental clinics.

The study participants were recruited from eight randomly selected private dental clinics from each of the five regions of Jeddah, including eastern, western, central, northern, and southern areas. All dental assistants who agreed to participate in the study were included without any exceptions. Informed consent was obtained from all the participants, and data confidentiality has been maintained.

\section{Study questionnaire}

The study questionnaire was developed in English language based on previous literature $[5,10-12,15,16]$. The face validity of the questionnaire and feasibility were established prior to data collection. We collected data on age, gender, years of experience (3 years or less/more than 3 years), nature of the clinic worked (e.g., endodontics, prosthodontics, and surgery), worked in more than one clinic $(1 / 2 / 3$ or more), duration of workday ( $8 \mathrm{~h}$ or less/more than $8 \mathrm{~h}$ ), average number of patients attended per day (12 or less/more than 12), history of needlestick and sharp injuries (yes/no), frequency of past injuries, instrument causing the injury, procedure causing the injury, status of instrument contamination, injury reporting (yes/no), test for infection (yes/no), and receipt of post-exposure prophylaxis (yes/no).

Information on performing various clinical procedures (yes/no), such as needle recapping, needle exchange, transmitting instruments, picking up instruments, washing sharp instruments, sharp instrument disposal, local anesthesia administration, wound suturing, and scaling every working day, was also obtained. Dental assistants who answered yes to six or more questions were considered to be preforming high-risk procedures, and the rest of them were deemed performing low-risk procedures daily. We used this criterion to create a new reliable composite variable for high-risk procedures (high/low) in our analyses (Cronbach's alpha $=0.79$ ).

Compliance of dental assistants to various infection control protocols (yes/no), such as vaccination of dental assistants against HBV; use of personal protective equipment like gloves, face masks, and gowns; protective glasses and face shields; protective wrap; needle recapping using one-hand technique; using disposable burs; and proper waste disposal procedure, was also obtained.

Level of knowledge on infection control and transmission of infectious diseases among dental assistants was assessed based on responses to questions seeking information on whether the assistants knew the temperature and time required for complete sterilization; knowing the risk of transmission of HBV, HBC, and HIV; HBV viability on clinic surfaces; and whether they knew which infectious disease has the highest rate of transmission in saliva. A composite variable for knowledge was constructed based on the final score calculated by coding the correct answers with 1 , and adding up all seven responses to obtain the final score. Participants who scored 3 or less were considered to have poor knowledge level, whereas participants who scored more than 3 were classified as having good level of knowledge. The composite variable for level of knowledge was reliable (Cronbach's alpha $=0.65$ ) in representing knowledge factors in our analysis. Participants also provided data on whether they had formal infection control training (yes/no) and whether the dental hospital they worked in had an infection control unit (yes/no). 


\section{Statistical analysis}

The data were analyzed using SAS software version 9.4 (SAS Institute Inc., Cary, NC, USA). Frequency counts and percentages for categorical variables, and mean and standard deviation (SD) for continuous variable were computed. The Clopper-Pearson exact tests were used to construct $95 \%$ confidence intervals for proportion. Pearson's chi-squared test (or Fisher's exact tests for smaller samples) and $p$ values were used to assess the independence of various sample characteristics by NSI experience (yes/no).

To determine associated factors for experiencing NSIs, the unadjusted odd ratios (uORs), adjusted odds ratios (aORs), and their respective 95\% confidence intervals (95\% CIs) were computed using logistic regression analysis. The study subjects missing data on characteristics considered in our models were excluded in the analyses. The calibration of multivariate model was assessed using the Hosmer and Lemeshow goodness-of-fit test, and multicollinearity was assessed based on collinearity indices, Eigen values, and variable decomposition proportions. The statistical significance was based on a $p$ value of 0.05 or less.

\section{Results}

Our analysis was based on a sample of 450 dental assistants who participated in our survey (among 500 eligible subjects invited to participate). The participants were predominantly female (96\%) with an average age of 31.1 years $(\mathrm{SD} \pm 6.9)$. A total of 134 participants experienced needlestick and sharp injuries $(29.8 \%, 95 \%$ CI $25.6-$ $34.2 \%)$. A significant number of these injuries were caused by needles (53\%), mainly during recapping (23\%). Approximately $63 \%$ of the NSIs were not reported, 35\% underwent testing post-injury, and 19\% of the dental assistants received post-exposure prophylaxis for their injury.

The descriptive statistics for various characteristics of study population were reported in Table 1 as frequencies and percentages. About $50 \%$ of study subjects were working in three or more clinical sub-specialties in a dental clinic. Results also revealed that the majority of subjects worked $8 \mathrm{~h}$ or less in a day $(76 \%)$, attended 12 patients or less (57.1\%), had less than 3 years of work experience $(55.1 \%)$, and had poor knowledge of infection control and disease transmission process (58\%). Experiencing NSIs in a dental clinic was dependent on workers receiving anti-HBV vaccination and the presence of infection control unit in a dental clinic $(p<0.05)$.

Table 2 shows the unadjusted ( $\mathrm{uOR}$ ) and adjusted odds ratios (aOR) and their 95\% confidence intervals (CIs) for the association between various population characteristics and NSI experience. Dental assistants with poor knowledge of infection control and disease transmission process experienced 1.9-fold higher risk of
NSIs than those with good knowledge (aOR $=1.87,95 \%$ CI 1.18-2.97). Lack of infection control unit in the dental clinic was significantly associated with NSI experience in our sample $(\mathrm{aOR}=2.28$, 95\% CI 1.45-3.57). Subjects that were not vaccinated for HBV and attending 12 patients or less in a day were significantly associated with higher NSI experience; adjusted odds ratios (95\% CI) were 1.89 (1.05-3.41) and 1.63 (1.03-2.56), respectively. The final model was well calibrated $(p=0.5451$, Hosmer and Lemeshow goodness-of-fit test), and multicollinearity was not an issue.

\section{Discussion}

The present study determined that approximately 30\% of dental assistants working in private dental clinics in Saudi Arabia experienced at least one NSI during their working life. We identified several key factors associated with NSI experience among dental assistants, including vaccination against $\mathrm{HBV}$ infection, attending 12 patients or less in a day, poor knowledge of infection control and disease transmission process, and lack of infection control unit in dental clinic.

The prevalence of NSI experience among dental assistants in Saudi Arabia was similar to those in Iran (31\%) [17], but considerably lower than the prevalence (75\%) reported in Germany [18]. Our results were consistent with prior studies that reported needles as the main source of NSI [13, 18-22]. In a previous study conducted among nurses working in a regular university hospital in Saudi Arabia [23], 45\% of nurses experienced an NSI indicating the prevalent nature of this preventable condition in Saudi Arabia [23].

Forty-two percent of dental assistants in the current study reported good level of knowledge by answering many questions in the survey correctly. This percentage was somewhat similar to that reported among dental assistants in Iran, where dentists' knowledge score was 4.88 out of 10 [17]. In the current study, increased level of knowledge of infectious disease transmission was found to be significantly associated with lower risks of NSIs. These results were similar to those reported in a study of Taiwan participants [11] which showed that those who lacked knowledge about oral signs of HIV were at a $60 \%$ increased risk of suffering a NSI. The present study evaluated knowledge of a number of variables such as knowledge of temperature and time required for complete sterilization, and knowledge of the risk of transmission of HBV, HVC, and HIV. These reflect increased awareness of knowledgeable dental assistants regarding factors influencing infection at dental clinics, which might have contributed to their decreased risk of NSI.

Treating a lower number of patients per day was found to be positively associated with higher NSIs. This 
Table 1 Descriptive data of study sample by history of needlestick and sharp injury (NSI) experience

\begin{tabular}{|c|c|c|c|c|c|}
\hline \multirow[t]{3}{*}{ Characteristic } & \multirow[t]{3}{*}{ Category } & \multicolumn{3}{|c|}{ Number of subjects (\%) } & \multirow[t]{3}{*}{$p$ value $^{*}$} \\
\hline & & \multirow[t]{2}{*}{ All $(n=450)$} & \multicolumn{2}{|l|}{ History of NSI } & \\
\hline & & & Yes $(n=134)$ & No $(n=316)$ & \\
\hline \multirow[t]{3}{*}{ Number of clinics worked } & One & $165(36.7)$ & $46(34.3)$ & $119(37.7)$ & \multirow[t]{3}{*}{0.3359} \\
\hline & Two & $58(12.9)$ & $22(16.4)$ & $36(11.4)$ & \\
\hline & 3 or more & $227(50.4)$ & $66(49.3)$ & $161(50.9)$ & \\
\hline \multirow[t]{2}{*}{ Daily working hours } & $>8 \mathrm{~h}$ & $108(24.0)$ & $25(18.7)$ & $83(26.3)$ & \multirow[t]{2}{*}{0.0839} \\
\hline & $8 \mathrm{~h}$ or less & $342(76.0)$ & $109(81.3)$ & $233(73.7)$ & \\
\hline \multirow{2}{*}{$\begin{array}{l}\text { Number of patients attended } \\
\text { per day }\end{array}$} & $>12$ & $193(42.9)$ & $48(35.8)$ & $145(45.9)$ & \multirow[t]{2}{*}{0.0485} \\
\hline & 12 or less & $257(57.1)$ & $86(64.2)$ & $171(54.1)$ & \\
\hline \multirow[t]{2}{*}{ Years of experience } & 3 years or less & $248(55.1)$ & $66(49.3)$ & $182(57.6)$ & \multirow[t]{2}{*}{0.1038} \\
\hline & $>3$ years & $202(44.9)$ & $68(50.7)$ & $134(42.4)$ & \\
\hline \multirow{2}{*}{$\begin{array}{l}\text { Performing procedures carrying } \\
\text { high risk }\end{array}$} & No & $168(37.3)$ & $46(34.3)$ & $122(38.6)$ & \multirow[t]{2}{*}{0.3908} \\
\hline & Yes & $282(62.7)$ & $88(65.7)$ & $194(61.4)$ & \\
\hline \multirow[t]{2}{*}{ Anti-hepatitis B vaccination } & No & $64(14.2)$ & $30(22.4)$ & $34(10.8)$ & \multirow[t]{2}{*}{0.0012} \\
\hline & Yes & $386(85.8)$ & $104(77.6)$ & $282(89.2)$ & \\
\hline \multirow[t]{2}{*}{ Wore gowns, mask, and gloves } & No & $74(16.4)$ & 29 (21.6) & $45(14.2)$ & \multirow[t]{2}{*}{0.0528} \\
\hline & Yes & $376(83.6)$ & $105(78.4)$ & $271(85.8)$ & \\
\hline \multirow[t]{2}{*}{ Used eye and facial protection } & No & $83(18.4)$ & $32(23.9)$ & $51(16.1)$ & \multirow[t]{2}{*}{0.0528} \\
\hline & Yes & $367(81.6)$ & $102(76.1)$ & $265(83.9)$ & \\
\hline \multirow[t]{2}{*}{ Used protective films } & No & $65(14.4)$ & $22(16.4)$ & $43(13.6)$ & \multirow[t]{2}{*}{0.4381} \\
\hline & Yes & $385(85.6)$ & $112(83.6)$ & $273(86.4)$ & \\
\hline \multirow[t]{2}{*}{ Used disposable burs } & No & $197(43.8)$ & $67(50.0)$ & $130(41.1)$ & \multirow[t]{2}{*}{0.0832} \\
\hline & Yes & $253(56.2)$ & $67(50.0)$ & $186(58.9)$ & \\
\hline \multirow[t]{2}{*}{ Used high-volume suction } & No & $41(9.1)$ & $16(11.9)$ & $25(7.9)$ & \multirow[t]{2}{*}{0.1744} \\
\hline & Yes & $409(90.9)$ & $118(88.1)$ & $291(92.1)$ & \\
\hline \multirow{2}{*}{$\begin{array}{l}\text { Recapped needles by one-hand } \\
\text { technique }\end{array}$} & No & $32(7.1)$ & $14(10.4)$ & $18(5.7)$ & 0.0729 \\
\hline & Yes & $418(92.9)$ & $120(89.6)$ & $298(94.3)$ & \\
\hline Knowledge of infection control procedures & Good & $189(42.0)$ & $41(30.6)$ & $148(46.8)$ & 0.0014 \\
\hline & Poor & $261(58.0)$ & $93(69.4)$ & $168(53.2)$ & \\
\hline Formal infection control training & No & $119(26.4)$ & $36(26.9)$ & $83(26.3)$ & 0.8950 \\
\hline & Yes & 331 (73.6) & $98(73.1)$ & $233(73.7)$ & \\
\hline Infection control unit in the clinic & No & $206(45.8)$ & $82(61.2)$ & $124(39.2)$ & $<0.0001$ \\
\hline & Yes & $234(52.0)$ & $52(38.8)$ & $182(57.6)$ & \\
\hline & Missing & $10(2.2)$ & $0(0.0)$ & $10(3.2)$ & \\
\hline
\end{tabular}

${ }^{*} p$ value was based on Pearson's chi-squared test to evaluate the independence of sample characteristic and NSI experience

can be attributed to the fact that those treating more patients may have accumulated more experience in handling devices and efficiently performing the different tasks without enduring more risk of NSI. Our findings are in contrast to the findings of the study in Taiwan, in which dentists were 3.57 times more likely to suffer an NSI when treating more than 30 patients [11]. In addition, Ebrahimi et al. reported that there was no relationship between treating the number of patents and the risk of NSI [17]. However, in agreement with our current study, another study conducted in Germany reported that treating more patients was associated with lower risk [18]. Although the collective evidence has been inconsistent, the varying risk observed among different professions and geographic regions warrants further investigation of the role of patient load on NSI risk.

The risk of NSIs was consistently higher among dental workers, in several countries, who exhibited poor compliance to infection control protocols [11, 12, 24-26]. Universal infection control protocols [15] were developed 
Table 2 Unadjusted (UOR) and adjusted odds ratios (aOR) and their respective 95\% confidence intervals (95\% Cls) for the relationship between characteristics of study population and needlestick and sharp injury (NSI) experience

\begin{tabular}{|c|c|c|c|c|c|c|c|}
\hline \multirow[t]{2}{*}{ Characteristic } & \multirow[t]{2}{*}{ Category } & \multicolumn{3}{|c|}{ Unadjusted odds ratios } & \multicolumn{3}{|c|}{ Adjusted odds ratios } \\
\hline & & $\mathrm{UOR}$ & $95 \% \mathrm{Cl}$ & $p$ value & $\mathrm{aOR}$ & $95 \% \mathrm{Cl}$ & $p$ value \\
\hline \multirow[t]{3}{*}{ Number of clinics worked } & $\mathrm{One}^{+}$ & 1.00 & & & 1.00 & & \\
\hline & Two & 1.47 & $0.78-2.77$ & 0.2283 & 1.26 & $0.64-2.49$ & 0.5009 \\
\hline & 3 or more & 1.00 & $0.64-1.57$ & 0.9943 & 1.00 & $0.61-1.62$ & 0.9877 \\
\hline \multirow[t]{2}{*}{ Daily working hours } & $>8 \mathrm{~h}^{\dagger}$ & 1.00 & & & 1.00 & & \\
\hline & $8 \mathrm{~h}$ or less & 1.60 & $0.97-2.64$ & 0.0685 & 1.46 & $0.82-2.58$ & 0.1949 \\
\hline \multirow[t]{2}{*}{ Number of patients attended per day } & $>12^{\dagger}$ & 1.00 & & & 1.00 & & \\
\hline & 12 or less & 1.55 & $1.02-2.36$ & $0.0398^{*}$ & 1.63 & $1.03-2.56$ & $0.0358^{*}$ \\
\hline \multirow[t]{2}{*}{ Years of experience } & $>3$ years & 1.39 & $0.93-2.10$ & 0.1095 & 1.48 & $0.95-2.31$ & 0.0853 \\
\hline & 3 years or less ${ }^{\dagger}$ & 1.00 & & & 1.00 & & \\
\hline \multirow[t]{2}{*}{ Performing procedures carrying high risk } & $\mathrm{No}^{+}$ & 1.00 & & & 1.00 & & \\
\hline & Yes & 1.14 & $0.74-1.74$ & 0.5571 & 1.29 & $0.82-2.04$ & 0.2646 \\
\hline \multirow[t]{2}{*}{ Anti-hepatitis B vaccination } & No & 2.31 & $1.34-3.96$ & $0.0024^{*}$ & 1.89 & $1.05-3.41$ & $0.0333^{*}$ \\
\hline & Yes $^{\dagger}$ & 1.00 & & & 1.00 & & \\
\hline \multirow[t]{2}{*}{ Wore gowns, mask, and gloves } & $\mathrm{No}^{+}$ & 1.60 & $0.95-2.69$ & 0.0750 & 1.37 & $0.67-2.79$ & 0.3886 \\
\hline & Yes $^{\dagger}$ & 1.00 & & & 1.00 & & \\
\hline \multirow[t]{2}{*}{ Used eye and facial protection } & No & 1.61 & $0.97-2.65$ & 0.0629 & 1.14 & $0.60-2.18$ & 0.6834 \\
\hline & Yes $^{\dagger}$ & 1.00 & & & 1.00 & & \\
\hline \multirow[t]{2}{*}{ Used protective films } & No & 1.20 & $0.69-2.10$ & 0.5202 & 0.83 & $0.43-1.58$ & 0.5642 \\
\hline & Yes $^{\dagger}$ & 1.00 & & & 1.00 & & \\
\hline \multirow[t]{2}{*}{ Used disposable burs } & No & 1.37 & $0.91-2.06$ & 0.1282 & 1.20 & $0.77-1.88$ & 0.4239 \\
\hline & Yes $^{\dagger}$ & 1.00 & & & 1.00 & & \\
\hline \multirow[t]{2}{*}{ Used high-volume suction } & No & 1.59 & $0.82-3.11$ & 0.1717 & 1.14 & $0.54-2.42$ & 0.7288 \\
\hline & Yes $^{\dagger}$ & 1.00 & & & 1.00 & & \\
\hline \multirow[t]{2}{*}{ Recapped needles by one-hand technique } & No & 1.87 & $0.90-3.87$ & 0.0938 & 1.59 & $0.69-3.62$ & 0.2732 \\
\hline & Yes $^{\dagger}$ & 1.00 & & & 1.00 & & \\
\hline \multirow[t]{2}{*}{ Knowledge of infection control procedures and disease transmission } & Good $^{+}$ & 1.00 & & & 1.00 & & \\
\hline & Poor & 2.10 & $1.36-3.23$ & $0.0007^{*}$ & 1.87 & $1.18-2.97$ & $0.0082^{*}$ \\
\hline \multirow[t]{2}{*}{ Formal infection control training } & No & 1.15 & $0.72-1.83)$ & 0.5500 & 0.86 & $0.52-1.45$ & 0.5778 \\
\hline & Yes $^{\dagger}$ & 1.00 & & & 1.00 & & \\
\hline \multirow[t]{2}{*}{ Infection control unit in the clinic } & No & 2.31 & $1.53-3.51$ & $<0.0001^{*}$ & 2.28 & $1.45-3.57$ & $0.0003^{*}$ \\
\hline & $\mathrm{Yes}^{\dagger}$ & 1.00 & & & 1.00 & & \\
\hline
\end{tabular}

${ }^{*} p$ values reported were significant based on significance level of 0.05

${ }^{\dagger}$ Reference category for the variable

based on evidence of effectiveness to prevent incidents of infectious disease transmission and to protect the patient and healthcare workers, so it is naturally presumable that a negative relationship exists between compliance and injuries. Assistants adhering to protocols also indicate that they are more cautious; thus, lower numbers of injuries will affect them. It is noteworthy that vaccination against HBV was the predominant infection control protocol influencing lower risk of NSI experience among dental assistants in our study. In a study of the global risk of hepatitis $\mathrm{B}$ among healthcare workers, the dental community was found to have the highest infection risk of all healthcare personnel [27]. Given this finding, and significant burden of HBV infection in the Far East, Middle East, Africa, and parts of South America (HBV surface antigen rates ranging between 8 and 15\%), HBV vaccination among HCWs in general and dental staff in particular is an important preventive measure [28]. Therefore, anti-HBV vaccine should be made mandatory for all healthcare workers in both public and private care settings in Saudi Arabia.

It is interesting to note that lack of infection control unit within the dental clinic was associated with 
increased risk of NSI. This can be also explained within the scope of compliance to infection control protocols. Not having an infection control unit may be associated with overall lack of training or low levels of awareness of the dental staff to the issues of infection control and occupational safety or both. This is in contrast to other clinics which may have such a unit and thereby have better awareness of occupational safety.

The present study addressed the risk of NSIs among dental assistants for the first time in Saudi Arabia. Unlike previous studies that mainly focused on NSI risk among HCWs in public sector [29-31], our study contributed to much needed background data in private care settings. Furthermore, we assessed NSI risk for wide-ranging associated factors to inform public health efforts directed at mitigating NSIs in HCWs. The current study did not explore the prevalence and factors leading to NSI among dentists. This occupational group can be at high risk due to the nature of their job including frequent handling of needles and other sharp objects. A recent study conducted in three types of dental clinics in Riyadh, Saudi Arabia [32], found the prevalence NSI among dentists of about $21 \%$. This was slightly lower than the prevalence in dental assistants of $29 \%$ reported in the current study. It is expected that risk factors such as education, work load, training, and other factors differ between dentists and dental assistants. Indeed, results from the study [32] suggested that more professional experience and greater compliance with infection control procedures were associated with lower risk of NSI.

This study was subjected to some limitations. Foremost, the readers should refrain from drawing causal inferences due to the cross-sectional study design. However our findings contributed to the knowledge of NSIs in dental assistants and have the potential to inform future studies in this vulnerable workforce. Although one should be cautious about generalizing findings from one city to the entire country, we expect our results to be representative of private dental sector in the country owing to the diversity of clinic types included, governance structure, and cultural homogeneity in Saudi population. Self-reported data was subject to recall bias, but we would expect minimal effect on our results owing to routine and current practices tested in the questionnaire.

Another limitation that this study did not explore was the prevalence and associated factors of NSI among dentists due to limited resources. Such information would be valuable in comparing the risk between the two groups in the dental occupation and may be explored in future studies.

\section{Conclusions}

About three in ten dental assistants working in private dental clinics experienced at least one NSI during their lifetime, indicating the prevalent nature of this preventable condition in Saudi Arabia. Our study highlighted NSI risk among participants lacking proper knowledge on infection control and disease transmission in dental clinic setting, and non-compliance to hepatitis B vaccination. This warrants proper training of dental personnel in infection control protocols at the workplace [33, 34]. Patient load as a factor influencing NSI should be further explored in future research owing to inconsistent evidence worldwide. The positive effect of infection control unit in reducing the experience of NSIs should encourage dental clinics towards the establishment of independent infection control units in their facility. Overall, our study contributed to the knowledge of NSIs among dental assistants in often overlooked private care facilities.

\section{Abbreviations}

aOR: Adjusted odds ratio; Cl: Confidence interval; HBV: Hepatitis B virus; HCV: Hepatitis C virus; HCWs: Healthcare workers; HIV: Human immunodeficiency virus; NSI: Needlestick and sharp injury; SD: Standard deviation; uOR: Unadjusted odds ratio; WHO: World Health Organization

\section{Acknowledgements}

We would like to thank the private clinic management for their cooperation and dental assistants for participating in our study.

\section{Authors' contributions}

LA and MA designed the study and analyzed and interpreted the data. LA collected the data. NY performed the data analysis and helped drafting the manuscript with contributions from $L A, O A$, and MA. All authors reviewed and approved the manuscript submitted to the journal and are accountable for all aspects of the work in ensuring that questions related to the accuracy or integrity of any part of the work are appropriately investigated and resolved. All authors read and approved the final manuscript.

\section{Funding}

This project has no funding sources.

Availability of data and materials

The datasets used and/or analyzed during the current study are available from the corresponding author on reasonable request.

Ethics approval and consent to participate

Ethics approval for this study was provided by the institutional review board (IRB) at King Abdullah International Medical Research Center (KAIMRC) in Riyadh under protocol number SP17-148-R. Informed consent was obtained from all the participants.

Consent for publication

Not applicable

\section{Competing interests}

The authors declare that they have no competing interests.

\section{Author details}

${ }^{1}$ King Abdullah International Medical Research Center (KAIMRC), Riyadh, Kingdom of Saudi Arabia. ${ }^{2}$ Department of Community and Environmental Health, College of Public Health and Health Informatics, King Saud bin Abdulaziz University for Health Sciences, Mail Code 2350, P.O. Box 22490, Riyadh 11426, Kingdom of Saudi Arabia. ${ }^{3}$ College of Dentistry, King Abdulaziz University, Jeddah, Kingdom of Saudi Arabia. 
Received: 5 February 2019 Accepted: 3 September 2019

Published online: 10 October 2019

\section{References}

1. Wilburn SQ, Eijkemans G. Preventing needlestick injuries among healthcare workers: a WHO-ICN collaboration. Int J Occup Environ Health. 2004;10(4): 451-6 https://doi.org/10.1179/oeh.2004.10.4.451.

2. World Health Organization. The world health report 2002 - reducing risks, promoting healthy life. Geneva: World Health Organization; 2002. Available from: http://www.who.int/whr/2002/en/

3. National Institute for Occupational Safety and Health (NIOSH). Preventing needlestick injuries in health care settings. Cincinnati: National Institute for Occupational Safety and Health; 1999. p. 2000-108. Available from: https:// www.cdc.gov/niosh/docs/2000-108/pdfs/2000-108.pdf

4. Collins $\mathrm{CH}$, Kennedy DA. Microbiological hazards of occupational needlestick and 'sharps' injuries. J Appl Bacteriol. 1987;62(5):385-402.

5. Rapiti E, Prüss-Üstün A, Hutin Y. Sharps injuries: assessing the burden of disease from sharps injuries to health-care workers at national and local levels. Geneva: World Health Organization; 2005. Available from: http:// www.who.int/quantifying_ehimpacts/publications/ebd11.pdf?ua=1

6. Lee JJ, Kok SH, Cheng SJ, Lin LD, Lin CP. Needlestick and sharps injuries among dental healthcare workers at a university hospital. J Formos Med Assoc. 2014;113(4):227-33 https://doi.org/10.1016/j.jfma.2012.05.009

7. Alavian SM, Izadi M, Zare AA, Lankarani MM, Assari S, Vardi MM. Survey of the level of anti-HBs antibody titer in vaccinated Iranian general dentists. Spec Care Dentist. 2008;28(6):265-70 https://doi.org/10.1111/j.1754-4505. 2008.00052.x.

8. Centers for Disease Control and Prevention (CDC). Stop sticks campaign, https://www.cdc.gov/niosh/stopsticks/sharpsinjuries.html; 2011 (accessed 21 Mar 2018).

9. Prüss-Üstün A, Rapiti E, Hutin YJF. Sharps injuries: global burden of disease from sharps injuries to health-care workers. Geneva: World Health Organization; 2003. Available from: http://www.who.int/quantifying_ ehimpacts/publications/en/sharps.pdf?ua=1

10. Pruss-Ustun A, Rapiti E, Hutin Y. Estimation of the global burden of disease attributable to contaminated sharps injuries among health-care workers. Am J Ind Med. 2005:48(6):482-90 https://doi.org/10.1002/ajim.20230.

11. Cheng HC, Su CY, Yen AM, Huang CF. Factors affecting occupational exposure to needlestick and sharps injuries among dentists in Taiwan: a nationwide survey. PLoS One. 2012;7(4):e34911 https://doi.org/10.1371/ journal.pone.0034911.

12. Kakizaki M, Ikeda N, Ali M, Enkhtuya B, Tsolmon M, Shibuya K, et al. Needlestick and sharps injuries among health care workers at public tertiary hospitals in an urban community in Mongolia. BMC Res Notes. 2011;4(184) https://doi.org/10.1186/1756-0500-4-184

13. Salehi AS, Garner P. Occupational injury history and universal precautions awareness: a survey in Kabul hospital staff. BMC Infect Dis. 2010;10(19) https://doi.org/10.1186/1471-2334-10-19.

14. Marusic V, Markovic-Denic L, Djuric O, Protic D, Dubljanin-Raspopovic E. Knowledge about blood-borne pathogens and the prevalence of needle stick injuries among medical students in Serbia. Zdr Varst. 2017;56(3):179-84 https://doi.org/10.1515/sjph-2017-0024.

15. World Health Organization. Dept. of Blood Safety and Clinical Technology. Aide-memoire for a strategy to protect health workers from infection with bloodborne viruses. Geneva: World Health Organization; 2003. Available from: http://apps.who.int/iris/handle/10665/68354

16. Shuval K, Finley CE, Barlow CE, Gabriel KP, Leonard D, Kohl HW 3rd. Sedentary behavior, cardiorespiratory fitness, physical activity, and cardiometabolic risk in men: the cooper center longitudinal study. Mayo Clin Proc. 2014;89(8):1052-62 https://doi.org/10.1016/j.mayocp.2014.04.026.

17. Ebrahimi S, Shadman N, Ghaempanah I. Needlestick injuries in dentists and their assistants in Kerman, Iran: prevalence, knowledge, and practice. J Oral Health Oral Epidemiol. 2013;2(1):23-7.

18. Wicker S, Rabenau HF. Occupational exposures to bloodborne viruses among German dental professionals and students in a clinical setting. Int Arch Occup Environ Health. 2010;83(1):77-83 https://doi.org/10.1007/ s00420-009-0452-3

19. Hussain JSA, Ram SM, Galinde J, RRK J. Occupational exposure to sharp instrument injuries among dental, medical and nursing students in Mahatma Gandhi Mission's Campus, Navi Mumbai, India. J Contemp Dentistry. 2012;2(2):1-10.
20. Osman T. Epidemiology of sharp instruments injuries at a dental school in Sudan. Int J Infect Control. 2014;10(4) https://doi.org/10.3396/ijic.v10i4.13335.

21. Bhardwaj A, Sivapathasundaram N, Yusof M, Minghat A, Swe K, Sinha N. The prevalence of accidental needle stick injury and their reporting among healthcare workers in orthopaedic wards in general hospital Melaka, Malaysia. Malays Orthop J. 2014;8(2):6-13 https://doi.org/10.5704/moj.1407.009.

22. Markovic-Denic L, Maksimovic N, Marusic V, Vucicevic J, Ostric I, Djuric D. Occupational exposure to blood and body fluids among health-care workers in Serbia. Med Princ Pract. 2015;24(1):36-41 https://doi.org/10.1159/000368234.

23. El-Hazmi M, Al-Majid F. Needle stick and sharps injuries among health care workers: a 5-year surveillance in a teaching center in Saudi Arabia. Biomedical Research. 2008;19(2):133-40

24. McCarthy GM, Koval JJ, MacDonald JK. Occupational injuries and exposures among Canadian dentists: the results of a national survey. Infect Control Hosp Epidemiol. 1999;20(5):331-6 https://doi.org/10.1086/501626.

25. Doebbeling BN, Vaughn TE, McCoy KD, Beekmann SE, Woolson RF, Ferguson $\mathrm{KJ}$, et al. Percutaneous injury, blood exposure, and adherence to standard precautions: are hospital-based health care providers still at risk? Clin Infect Dis. 2003;37(8):1006-13 https://doi.org/10.1086/377535.

26. Gershon RR, Pearson JM, Sherman MF, Samar SM, Canton AN, Stone PW The prevalence and risk factors for percutaneous injuries in registered nurses in the home health care sector. Am J Infect Control. 2009;37(7):52533 https://doi.org/10.1016/j.ajic.2008.10.022.

27. Cottone JA. The global challenge of hepatitis B: implications for dentistry. Int Dent J. 1991;41(3):131-41.

28. Mahboobi N, Agha-Hosseini F, Mahboobi N, Safari S, Lavanchy D, Alavian SM. Hepatitis B virus infection in dentistry: a forgotten topic. J Viral Hepat. 2010;17(5):307-16 https://doi.org/10.1111/j.1365-2893.2010.01284.x.

29. Ghanei Gheshlagh R, Aslani M, Shabani F, Dalvand S, Parizad N. Prevalence of needlestick and sharps injuries in the healthcare workers of Iranian hospitals: an updated meta-analysis. Environ Health Prev Med. 2018;23:44.

30. Cui Z, Zhu J, Zhang X, Wang B, Li X. Sharp injuries: a cross-sectional study among health care workers in a provincial teaching hospital in China. Environ Health Prev Med. 2018;23:2

31. Ishimaru T, Wada K, Hoang HTX, Bui ATM, Nguyen HD, Le H, Smith DR. Nurses' willingness to care for patients infected with HIV or Hepatitis B / C in Vietnam. Environ Health Prev Med. 2017;22:9.

32. Al-Zoughool M, Al-Shehri Z. Injury and infection in dental clinics: risk factors and prevention. Toxicol Ind Health. 2018;34(9):609-19.

33. Centers for Disease Control and Prevention (CDC). Evaluation of safety devices for preventing percutaneous injuries among health-care workers during phlebotomy procedures--Minneapolis-St. Paul, New York City, and San Francisco, 1993-1995. MMWR Morb Mortal Wkly Rep. 1997;46(2):21-5.

34. Jagger J. Reducing occupational exposure to bloodborne pathogens: where do we stand a decade later? Infect Control Hosp Epidemiol. 1996;17(9):573-5.

\section{Publisher's Note}

Springer Nature remains neutral with regard to jurisdictional claims in published maps and institutional affiliations.

Ready to submit your research? Choose BMC and benefit from:

- fast, convenient online submission

- thorough peer review by experienced researchers in your field

- rapid publication on acceptance

- support for research data, including large and complex data types

- gold Open Access which fosters wider collaboration and increased citations

- maximum visibility for your research: over $100 \mathrm{M}$ website views per year

At $\mathrm{BMC}$, research is always in progress.

Learn more biomedcentral.com/submissions 